\title{
Endovascular treatment of posterior cerebral artery aneurysms: a single center's experience of 55 cases
}

\author{
*Xuanfeng Qin, MD, PhD, Feng Xu, MD, PhD, Yashengjiang Maimaiti, MD, Yongtao Zheng, MD, \\ Bin $\mathrm{Xu}, \mathrm{MD}, \mathrm{PhD}$, Bing Leng, MD, PhD, and Gong Chen, MD, PhD
}

Department of Neurosurgery, Huashan Hospital, Shanghai Medical School, Fudan University, Shanghai, China

\begin{abstract}
OBJECTIVE Aneurysms of the posterior cerebral artery (PCA) are uncommon. To date, a limited number of studies have examined the outcomes of endovascular treatment for PCA aneurysms. The authors' aim in this study is to report their experience with the endovascular treatment of PCA aneurysms.

METHODS Between January 2007 and December 2014, 55 patients with 59 PCA aneurysms were treated using the endovascular approach at the authors' institution. Twenty-three patients had 25 saccular aneurysms, and 32 patients had 34 fusiform/dissecting aneurysms. The endovascular modalities included the following: 1) selective occlusion of the aneurysm $(n=22) ; 2)$ complete occlusion of the aneurysm and the parent artery $(n=20) ; 3)$ parent artery occlusion $(n=6)$; 4) partial coiling of the aneurysm and the parent artery $(n=5)$; and 5) occlusion of the dissecting aneurysm $\operatorname{sac}(n=2)$. RESULTS The immediate angiographic results included 45 complete occlusions (82\%), 2 nearly complete occlusions $(4 \%)$, and 8 incomplete occlusions (14\%). The mean follow-up period of 21.8 months in 46 patients showed 37 stable results, 6 further thromboses, and 3 recurrences. The final results included 41 complete occlusions ( $89 \%), 2$ nearly complete occlusions ( $4 \%$ ), and 3 incomplete occlusions $(7 \%)$. Procedure-related complications included the following: 1) rebleeding $(n=1) ; 2)$ infarction $(n=4)$; and 3$)$ perforation $(n=1)$. There was $1(1.8 \%)$ procedure-related death due to rebleeding, and $2(3.6 \%)$ non-procedure-related deaths due to severe subarachnoid hemorrhage. Clinical outcomes were excellent (Glasgow Outcome Scale 5) in 47 of 49 patients at the long-term follow-up.
\end{abstract}

CONCLUSIONS PCA aneurysms may be effectively treated by different endovascular approaches with favorable clinical and radiological outcomes. However, patients who present with severe SAH still have an overall poor prognosis. Partial coiling of the aneurysm and the parent artery is an attractive alternative treatment for patients who may not tolerate parent artery occlusion. Further study with a larger case series is necessary for validation of the durability and efficacy of this treatment.

https://thejns.org/doi/abs/10.3171/2016.1.JNS152447

KEY WORDS endovascular treatment; posterior cerebral artery; aneurysm; vascular disorders

A NEURYSMS involving the posterior cerebral artery (PCA) are relatively rare, accounting for approximately $0.7 \%$ to $2.3 \%$ of all intracranial aneurysms. ${ }^{13,15,18,35}$ Surgical treatment of PCA aneurysms is complicated and often associated with high rates of morbidity because of the complexity of the perforating branches from the PCA and their relationship with the cranial nerves and upper brainstem. ${ }^{6,22,32,33}$ Selective catheterization of the PCA and endovascular occlusion of the aneurysm is technically feasible, offering an alternative to surgical treatment. ${ }^{7,21,29,35}$ For fusiform distal PCA aneurysms, parent artery occlusion (PAO) can be performed due to good collateralization., $2,17,30$ However, fusiform aneurysms involving the proximal segment $\left(\mathrm{P}_{1}\right.$ and $\mathrm{P}_{1} / \mathrm{P}_{2}$ junction) or with a fetal-type PCA remain challenging. ${ }^{26,40}$ Moreover, published studies on PCA aneurysms treated by the endovascular approach comprise only a limited number of cases. In the present study, we retrospectively reviewed our experiences with endovascular treatment in a series of 55 patients with 59 PCA aneurysms. We reported

ABBREVIATIONS AVM = arteriovenous malformation; BOT = balloon occlusion test; GOS = Glasgow Outcome Scale; IVH = intraventricular hemorrhage; PAO = parent artery occlusion; $\mathrm{PCA}=$ posterior cerebral artery; $\mathrm{SAH}=$ subarachnoid hemorrhage.

SUBMITTED October 29, 2015. ACCEPTED January 27, 2016.

INCLUDE WHEN CITING Published online April 22, 2016; DOI: 10.3171/2016.1.JNS152447.

* Drs Feng Xu and Chen contributed equally to this work. 
the clinical presentations, characteristics, endovascular treatments, complications, and angiographic and clinical outcomes of PCA aneurysms.

\section{Methods \\ Patient Population}

Between January 2007 and December 2014, 3508 aneurysms were treated at our institution. Surgery was performed in 1393 cases, and 2115 aneurysms were treated by endovascular embolization. Of 3508 treated aneurysms, $59(1.7 \%)$ aneurysms in 55 patients were located on the PCA. All PCA aneurysms were treated endovascularly. There were 32 men and 23 women, ranging in age from 9 to 73 years (mean 47.5 years). Clinical presentation included subarachnoid hemorrhage (SAH) in 18 patients ( 2 of which were accompanied by an intracerebral hematoma), intraventricular hemorrhage (IVH) in 2 patients, headache in 17 patients, dizziness in 4 patients, mass effect on the peduncle resulting in contralateral weakness or numbness in 3 patients, visual changes in 2 patients ( 1 with blurriness and 1 with diplopia), ptosis in 2 patients, and in 7 patients the aneurysm was incidentally discovered (Table 1).

\section{Treatment Strategy}

For saccular PCA aneurysms with a well-defined neck, selective embolization of the aneurysm was performed with preservation of the parent vessel. For fusiform/dissecting aneurysms of the distal PCA, complete occlusion of the aneurysm together with the parent artery was generally intended.$^{17}$ In cases of giant fusiform/dissecting aneurysms, endovascular occlusion of the parent artery was performed. ${ }^{4}$ A balloon occlusion test (BOT) before permanent PCA occlusion was not routinely performed. For unruptured fusiform/dissecting aneurysms of the proximal PCA or fetal-type aneurysms, partial coiling of the aneurysm and the parent artery and reconstruction with stent-assisted coiling was performed.

\section{Endovascular Procedure}

All procedures were performed with the patient under general anesthesia. A 5.0- or 6.0-Fr Envoy guiding catheter (Cordis) was placed in the distal vertebral artery or internal carotid artery. Under fluoroscopic guidance, a microcatheter (Echelon-14; Covidien) was navigated to the orifice of the aneurysm. The aneurysm was embolized with detachable coils (Guglielmi Detachable Coils, Stryker; Microplex, Microvention; NXT fiber coils, Covidien). ${ }^{24}$ Patients who underwent stent-assisted coiling were given antiplatelet agents $(75 \mathrm{mg} /$ day clopidogrel and 300 $\mathrm{mg}$ /day aspirin) for 3 days before the procedure. These patients received systemic heparinization after placement of the sheath. Two types of stents were used to treat intracranial aneurysms, including Enterprise stents (Codman) and Solitaire AB stents (ev3). All stents were deployed following the standard procedure recommended by the manufacturer. The coil microcatheter was positioned into the aneurysm through the stent or before stent placement. Finally, the aneurysm was sequentially coiled using detachable coils.
TABLE 1. Patient characteristics*

\begin{tabular}{cc}
\hline Variable & Value \\
\hline No. of patients & 55 \\
\hline Age (yrs) & 47.5 \\
\hline Mean & $9-73$ \\
\hline Range & $32(58.2)$ \\
\hline Sex & $23(41.8)$ \\
\hline Male & $18(32.7)$ \\
\hline Female & $2(3.6)$ \\
\hline Presentation & $17(31)$ \\
\hline SAH & $4(7.3)$ \\
\hline IVH & $3(5.5)$ \\
\hline Headache & $2(3.6)$ \\
\hline Dizziness & $2(3.6)$ \\
\hline Mass effect & $7(12.7)$ \\
\hline Visual changes &
\end{tabular}

* Values are presented as number of patients (\%) unless otherwise indicated.

In patients who underwent occlusion of the parent artery and aneurysm, a microcatheter was advanced through the guiding catheter and inserted into the aneurysm. Depending on the availability of embolic materials, the parent artery and aneurysmal sac were occluded using coils alone, liquid embolics alone, or coils with a mixture of liquid embolics. Liquid embolics were added to coils to obtain a more stable occlusion. The parent artery was occluded very proximal to the aneurysm. Following the embolization procedure, vertebral angiography was performed to confirm occlusion of the parent artery and aneurysm. A control angiogram of the ipsilateral internal carotid artery was obtained to view collateral filling distal to the occlusion segment.

\section{Evaluations and Follow-Up}

The angiographic results were interpreted independently by 2 authors (F.X. and G.C.). In the case of disagreement, consensus was reached through discussion with the senior doctor (B.L.). The grades of aneurysmal occlusion subsequent to the coiling procedure were classified as complete (100\% occluded), nearly complete ( $\geq 95 \%)$ occluded), or incomplete $\left(<95 \%\right.$ occluded) ${ }^{39}$ Clinical outcomes were measured at discharge using the Glasgow Outcome Scale (GOS). ${ }^{32}$ The GOS terms were defined as follows: 5, good recovery (patient can lead a full and independent life with or without minimal neurological deficits); 4, moderately disabled (patient had neurological or intellectual impairment, but is independent); 3 , severely disabled (patient is conscious but totally dependent on others to get through daily activities); 2, vegetative survival (no obvious cortical function); 1, death. Long-term outcomes were also recorded. Follow-up included clinical and radiological assessments with digital subtraction angiography or MR angiography after 6 months. 


\section{Results}

\section{Aneurysm Characteristics}

Of the 59 aneurysms, 25 (42.3\%) were saccular, and 34 $(57.7 \%)$ were fusiform/dissecting (Table 2). Twenty aneurysms were ruptured, and 39 aneurysms were unruptured. Four of the 55 patients had multiple PCA aneurysms on the same side, 2 patients had 2 saccular aneurysms, and 2 patients had 2 fusiform aneurysms. Thirty aneurysms $(50.8 \%)$ were small $(<1.0 \mathrm{~cm}), 21(35.6 \%)$ were large $(\geq$ $1 \mathrm{~cm}$ and $\leq 2.5 \mathrm{~cm})$, and $8(13.6 \%)$ were giant $(>2.5 \mathrm{~cm})$. Each segment of the PCA was classified according to the classification of Zeal and Rhoton. ${ }^{41}$ The aneurysms were located as follows: $11(18.6 \%)$ at the $\mathrm{P}_{1}$ segment; $8(13.6 \%)$ at the junction of the $\mathrm{P}_{1}$ and $\mathrm{P}_{2}$ segments; 26 (45.8\%) at the $\mathrm{P}_{2}$ segment; $5(8.4 \%)$ at the junction of the $\mathrm{P}_{2}$ and $\mathrm{P}_{3}$ segments; $5(6.8 \%)$ at the $\mathrm{P}_{3}$ segment; and $4(6.8 \%)$ at the $\mathrm{P}_{4}$ segment.

Of the 55 patients, $14(25 \%)$ presented with associated findings, and 3 of these 14 patients had multiple findings. One patient had an occipital arteriovenous malformation (AVM) associated with multiple aneurysms on its major feeding arteries, including the PCA and anterior cerebral artery. One patient had a parietal AVM and an aneurysm involving the ophthalmic artery. Another patient had an aneurysm involving the $\mathrm{M}_{2}$ bifurcation and 1 involving the ophthalmic artery in addition to the distal PCA aneurysm. The remaining 11 patients had single lesions, which included 2 cases of moyamoya disease, 2 cases of intracranial stenosis, 2 aneurysms involving the ophthalmic artery, 1 aneurysm involving the anterior communicating artery, 1 aneurysm involving the posterior communicating artery, 1 cerebellar AVM, 1 frontal AVM, and 1 pineal tumor.

\section{Patients With Saccular Aneurysms}

In 20 of the 23 patients with saccular aneurysms, the aneurysm was selectively occluded with preservation of the parent artery using coils alone or in combination with stents (Fig. 1). None of the ruptured aneurysms were treated with stent-assisted coiling. Two patients (Cases 3 and 44) had multiple PCA aneurysms that are associated with an AVM. The aneurysm and the parent artery were occluded together with Onyx or a combination of coils and Onyx, respectively (Table 3). In the remaining patient (Case 4) with a large saccular aneurysm, the coils protruded into the parent artery during embolization. Thus, the parent artery was not secured. The patient suffered a small infarction in the left occipital lobe, resulting in right-sided homonymous hemianopia that resolved completely at the follow-up (Table 4).

The immediate angiographic results showed complete occlusion in $21(91.3 \%)$ patients, and nearly complete occlusion in $2(8.7 \%)$ patients. Angiographic follow-up, ranging from 4 to 86 months, was available in 20 patients. One patient died and, therefore, was not available for follow-up. One patient was lost to follow-up because of an address change. One patient refused to undergo follow-up angiography. Follow-up angiograms showed that recanalization occurred only in 1 of 18 patients (5.6\%) with a partially thrombosed aneurysm that received retreatment.
TABLE 2. Characteristics and distribution of PCA aneurysms*

\begin{tabular}{lrrc}
\hline & & \multicolumn{2}{c}{ PCA Aneurysms } \\
\cline { 3 - 4 } Characteristic & Total & Saccular & Fusiform/Dissecting \\
\hline No. of lesions & 59 & $25(42.3)$ & $34(57.7)$ \\
\hline Rupture state & & & \\
\hline Ruptured & $20(33.9)$ & $7(28)$ & $13(38.2)$ \\
\hline Unruptured & $39(66.1)$ & $18(72)$ & $21(53.8)$ \\
\hline Size & & & \\
\hline Small $(<1.0 \mathrm{~cm})$ & $30(50.8)$ & $19(76)$ & $11(32.4)$ \\
\hline Large & $21(35.6)$ & $5(20)$ & $16(47)$ \\
(btwn $\geq 1 \& \leq 2.5 \mathrm{~cm})$ & & & \\
\hline Giant $(>2.5 \mathrm{~cm})$ & $8(13.6)$ & $1(4)$ & $7(20.6)$ \\
\hline Location & & & \\
\hline $\mathrm{P}_{1}$ & $11(18.6)$ & $9(36)$ & $2(5.9)$ \\
\hline $\mathrm{P}_{1} / \mathrm{P}_{2}$ junction & $8(13.6)$ & $4(16)$ & $4(11.8)$ \\
\hline $\mathrm{P}_{2}$ & $26(45.8)$ & $6(24)$ & $20(58.8)$ \\
\hline $\mathrm{P}_{2} / \mathrm{P}_{3}$ junction & $5(8.4)$ & $1(4)$ & $4(11.8)$ \\
\hline $\mathrm{P}_{3}$ & $5(6.8)$ & $2(8)$ & $3(8.8)$ \\
\hline $\mathrm{P}_{4}$ & $4(6.8)$ & $3(12)$ & $1(2.9)$ \\
\hline
\end{tabular}

* Values are number of lesions (\%).

One patient with initial near-complete occlusion progressed to complete occlusion. The final results included 18 complete occlusions (90\%) and 2 nearly complete occlusions (10\%).

Twenty-two patients $(96 \%)$ were independent with a GOS score of 4 to 5 at discharge; the remaining patient died 2 weeks after occlusion of the aneurysm due to severe clinical status (Hunt and Hess Grade V SAH). Clinical follow-up was available for 21 patients. There were no instances of delayed deficits or rebleeding during the followup period. The clinical outcomes at the follow-up were excellent (GOS Score 5) for all these patients (Table 5).

\section{Patients With Fusiform/Dissecting Aneurysms}

In 18 of the 32 patients with fusiform/dissecting aneurysms, the aneurysm and the parent artery were completely occluded together. Two patients (Cases 19 and 45) had multiple aneurysms that were treated with occlusion of the proximal aneurysm together with the parent artery. Six patients with giant/large aneurysms were treated with PAO. Five patients who could not tolerate PAO were treated with partial coiling of the aneurysm and parent artery (Figs. 2-4). Early in our experience, 2 patients with a dissecting aneurysm were treated by occlusion of the aneurysm sac. The remaining 1 patient with an unruptured $P_{1}$ fusiform aneurysm was treated with stent-assisted coiling (Table 3).

The immediate angiographic results showed complete occlusion in $24(75 \%)$ patients and incomplete occlusion in $8(25 \%)$ patients. Among the patients with complete occlusion, 3 patients developed an infarction. One patient (Case 7) with a left $P_{2}$ dissecting aneurysm suffered right-limb numbness due to a thalamus infarction after occlusion of the aneurysm and the parent artery. One patient (Case 21) 

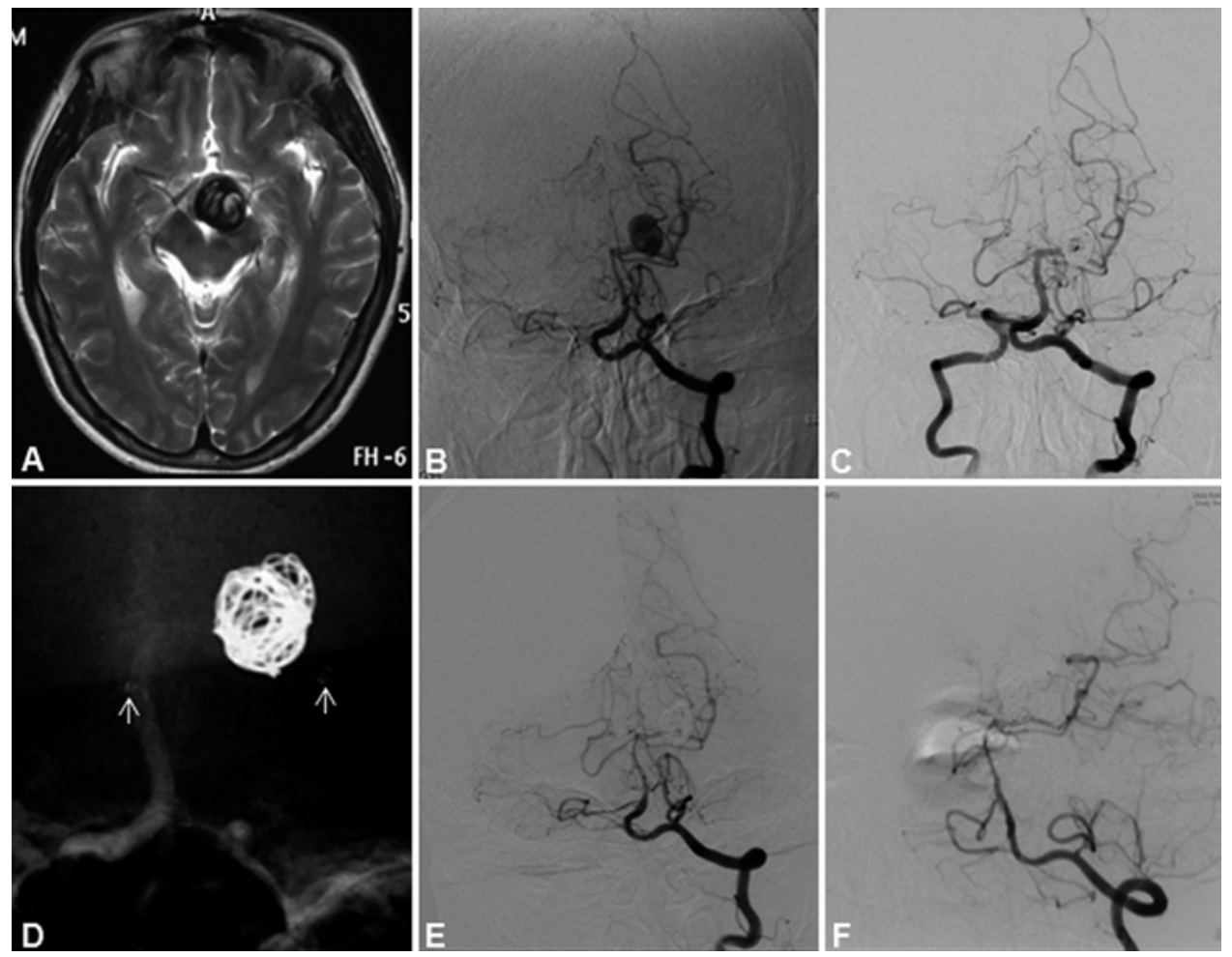

FIG. 1. Case 50. A: Axial T2-weighted MR image showing a large lesion compatible with the diagnosis of a partially thrombosed aneurysm. B: Vertebral angiogram demonstrating a saccular aneurysm arising from the $P_{1} / P_{2}$ junction of the left $P C A$. C: The aneurysm sac was nearly completely occluded by coil embolization. D: Unsubtracted image demonstrating the proximal and distal markers (arrows) of the Enterprise stent. $E$ and F: Thirteen-month follow-up angiograms in anteroposterior $(E)$ and oblique $(F)$ views showing complete obliteration of the aneurysm.

with a left $\mathrm{P}_{2}$ dissecting aneurysm developed contralateral homonymous hemianopia and limb numbness due to infarction in the occipital lobe and thalamus after occlusion of the aneurysm and parent artery. One patient (Case 35) with a large serpentine aneurysm of the $\mathrm{P}_{2}$ segment, who was treated with PAO, developed contralateral hemiparesis due to an infarction involving the thalamus and basal ganglion. We had 1 technical complication related to endovascular treatment, with perforation of a $\mathrm{P}_{1} / \mathrm{P}_{2}$ fusiform aneurysm in a woman who presented with headache (Case 11). The aneurysm was nearly completely occluded with minimal filling of the distal PCA. The patient suffered headache, but had no postoperative neurological deficit (Table 4).

Angiographic follow-up, ranging from 4 to 68 months, was available in 26 patients. Six patients did not have follow-up because of death $(\mathrm{n}=3)$, loss of communication $(n=1)$, or patient refusal $(n=2)$. Follow-up angiograms showed that recanalization occurred in $2(10 \%)$ of 20 patients. One patient (Case 8) with a ruptured $\mathrm{P}_{2}$-segment dissecting aneurysm was treated by occlusion of the aneurysm and parent artery. The entire dissected lesion was too long, and the endovascular occlusion mainly covered the proximal affected lesion. Long-term follow-up angiography revealed coil compaction and antegrade recanalization of the PCA. It was decided that no further intervention would be performed because the aneurysm appeared to remain stable. One patient (Case 45), who had multiple fusiform aneurysms, was treated by occlusion of only the proximal aneurysm together with the parent artery. Postoperative angiography demonstrated obliteration of the aneurysm and retrograde filling of the distal PCA segments. However, 8-month follow-up angiography showed minimal filling of the distal aneurysm by the collateral supply. Since there was no appropriate endovascular approach, we suggested the patient receive follow-up. In 3 patients with near-complete occlusion and 2 patients with incomplete occlusion, follow-up angiography showed complete occlusion of the aneurysm. In 1 patient with incomplete occlusion, follow-up angiography showed that the aneurysm remained stable. The final results included 23 complete occlusions (88\%) and 3 incomplete occlusions (12\%).

One patient with ruptured dissecting aneurysms died due to rebleeding within 24 hours after the initial endovascular treatment, whereas another patient died of the sequelae of SAH several days after treatment. The other 30 patients (94\%) were independent with GOS scores of 4 to 5 at discharge (Table 5). Clinical follow-up was available for 29 patients. One patient died of myocardial infarction at 1 year. Five moderately disabled patients (GOS Score 4) improved to good recovery (GOS Score 5), whereas 2 other patients with GOS Score 4 remained stable. All 21 patients who were discharged in good condition (GOS Score 5) remained stable at follow-up. 
TABLE 3. Endovascular treatment and angiographic results of PCA aneurysms*

\begin{tabular}{|c|c|c|c|}
\hline \multirow[b]{2}{*}{ Characteristic } & \multirow[b]{2}{*}{ Total } & \multicolumn{2}{|c|}{ PCA Aneurysms } \\
\hline & & Saccular & $\begin{array}{l}\text { Fusiform/ } \\
\text { Dissecting }\end{array}$ \\
\hline No. of patients & 55 & $23(41.8)$ & $32(58.2)$ \\
\hline Treatment & 55 & & \\
\hline Selective embolization & & 21 & 1 \\
\hline Aneurysm \& PA occlusion & & 2 & 18 \\
\hline PA occlusion & & 0 & 6 \\
\hline Aneurysm sac occlusion & & 0 & 2 \\
\hline Partial coiling of the aneurysm \& PA & & 0 & 5 \\
\hline Initial angiographic results & 55 & & \\
\hline Complete occlusion & & $21(91.3)$ & $24(75)$ \\
\hline Nearly complete occlusion & & $2(8.7)$ & 0 \\
\hline Incomplete occlusion & & 0 & $8(25)$ \\
\hline Follow-up angiography & 46 & 20 & 26 \\
\hline Complete occlusion & & $18(90)$ & $23(88)$ \\
\hline Nearly complete occlusion & & $2(10)$ & 0 \\
\hline Incomplete occlusion & & 0 & $3(12)$ \\
\hline
\end{tabular}

\section{Illustrative Cases Case 50}

A 59-year-old woman had a cerebral aneurysm that was incidentally discovered during a medical examination. MR imaging revealed a large partially thrombosed aneurysm in the basal cistern. Angiography demonstrated a saccular aneurysm arising from the $\mathrm{P}_{1} / \mathrm{P}_{2}$ junction of the left PCA (Fig. 1). In an effort to preserve the parent artery, we placed a $4.5 \times 22-\mathrm{mm}$ Enterprise stent through the upper basilar artery to the left PCA. The aneurysm sac was nearly completely occluded by coil embolization. Follow-up angiography 13 months later showed complete obliteration of the aneurysm sac.
TABLE 5. Clinical outcomes of patients with PCA aneurysms

\begin{tabular}{lcc}
\hline & \multicolumn{2}{c}{ No. of Patients } \\
\cline { 2 - 3 } GOS Score & At Discharge & $\begin{array}{c}\text { At Long-Term } \\
\text { Follow-Up* }\end{array}$ \\
\hline Saccular aneurysms & & \\
\hline 5 & 18 & 21 \\
\hline 4 & 4 & 0 \\
\hline 1 & 1 & 0 \\
\hline Fusiform/dissecting aneurysms & & \\
\hline 5 & 22 & 26 \\
\hline 4 & 8 & 1 \\
\hline 1 & 2 & \\
\hline * Two patients, including 1 patient with a saccular aneurysm and 1 patient with \\
a dissecting aneurysm, were lost to follow-up.
\end{tabular}

\section{Case 49}

A 44-year-old woman was admitted to our hospital with a 1-month history of dizziness. Axial T2-weighted MR imaging revealed a large flow void in the interpeduncular cistern that was suggestive of an aneurysm. Angiography showed a fusiform aneurysm at the $\mathrm{P}_{1}$ segment of the left PCA. In this case, the stent reconstruction strategy was difficult or impossible to use because of tortuosity and the small diameter of left distal PCA. Left internal carotid angiography revealed good filling of the $\mathrm{P}_{2}$ and distal segments of the PCA with retrograde filling of the aneurysm via the ipsilateral posterior communicating artery. Thus, occlusion of the aneurysm together with the parent artery was planned. A $4.5 \times 22-\mathrm{mm}$ Enterprise stent was deployed in the right $\mathrm{P}_{2}$ segment and extended down to the mid-basilar artery to keep the right PCA patent. The aneurysm was almost completely occluded with coils, resulting in minimal filling of the distal PCA. Postoperatively, the patient remained neurologically intact with normal CT imaging. Angiography performed at 16 months showed complete occlusion of the aneurysm and parent artery. The $\mathrm{P}_{2}$ and distal segments of the left PCA were supplied by the posterior communicating artery (Fig. 2).

TABLE 4. Procedure-related complications

\begin{tabular}{|c|c|c|c|c|c|c|c|c|c|}
\hline \multirow{2}{*}{$\begin{array}{l}\text { Case } \\
\text { No. }\end{array}$} & \multirow{2}{*}{$\begin{array}{c}\text { Age } \\
\text { (yrs)/Sex }\end{array}$} & \multirow{2}{*}{$\begin{array}{c}\text { Clinical } \\
\text { presentation }\end{array}$} & \multicolumn{3}{|c|}{ Aneurysm } & \multirow[b]{2}{*}{ Treatment } & \multirow[b]{2}{*}{ Complication } & \multirow{2}{*}{$\begin{array}{l}\text { Permanent } \\
\text { Morbidity }\end{array}$} & \multirow[b]{2}{*}{ Mortality } \\
\hline & & & Location & Type & Size & & & & \\
\hline 4 & $49 / F$ & Headache & Lt $P_{1}$ & Saccular & Large & Selective embolization & Occipital lobe infarct & No & No \\
\hline 7 & $29 / M$ & Dizziness & $\mathrm{Lt} \mathrm{P}_{2}$ & Dissecting & Large & Aneurysm \& PA occlusion & Thalamus infarct & No & No \\
\hline 11 & $56 / F$ & Headache & $\begin{array}{l}\text { Rt } P_{1} / \\
\quad P_{2}\end{array}$ & Fusiform & Large & $\begin{array}{l}\text { Partial coiling of aneurysm } \\
\text { \& PA }\end{array}$ & Perforation & No & No \\
\hline 21 & $61 / M$ & IVH & Lt $P_{2}$ & Dissecting & Large & Aneurysm \& PA occlusion & $\begin{array}{l}\text { Occipital lobe and } \\
\text { thalamus infarct }\end{array}$ & Yes (hemianopia) & No \\
\hline 33 & $68 / F$ & HH Grade II & $\mathrm{Rt} \mathrm{P}_{2}$ & Dissecting & Small & Aneurysm sac occlusion & Rebleeding & $\mathrm{NA}$ & Yes \\
\hline 35 & $71 / F$ & Mass effect & $\mathrm{Rt} \mathrm{P}_{2}$ & Fusiform & Large & PA occlusion & $\begin{array}{c}\text { Thalamus and basal } \\
\text { ganglion infarct }\end{array}$ & Yes (hemiparesis) & No \\
\hline
\end{tabular}

$\mathrm{HH}=$ Hunt and Hess grade; $\mathrm{NA}=$ not available; $\mathrm{PA}=$ parent artery. 

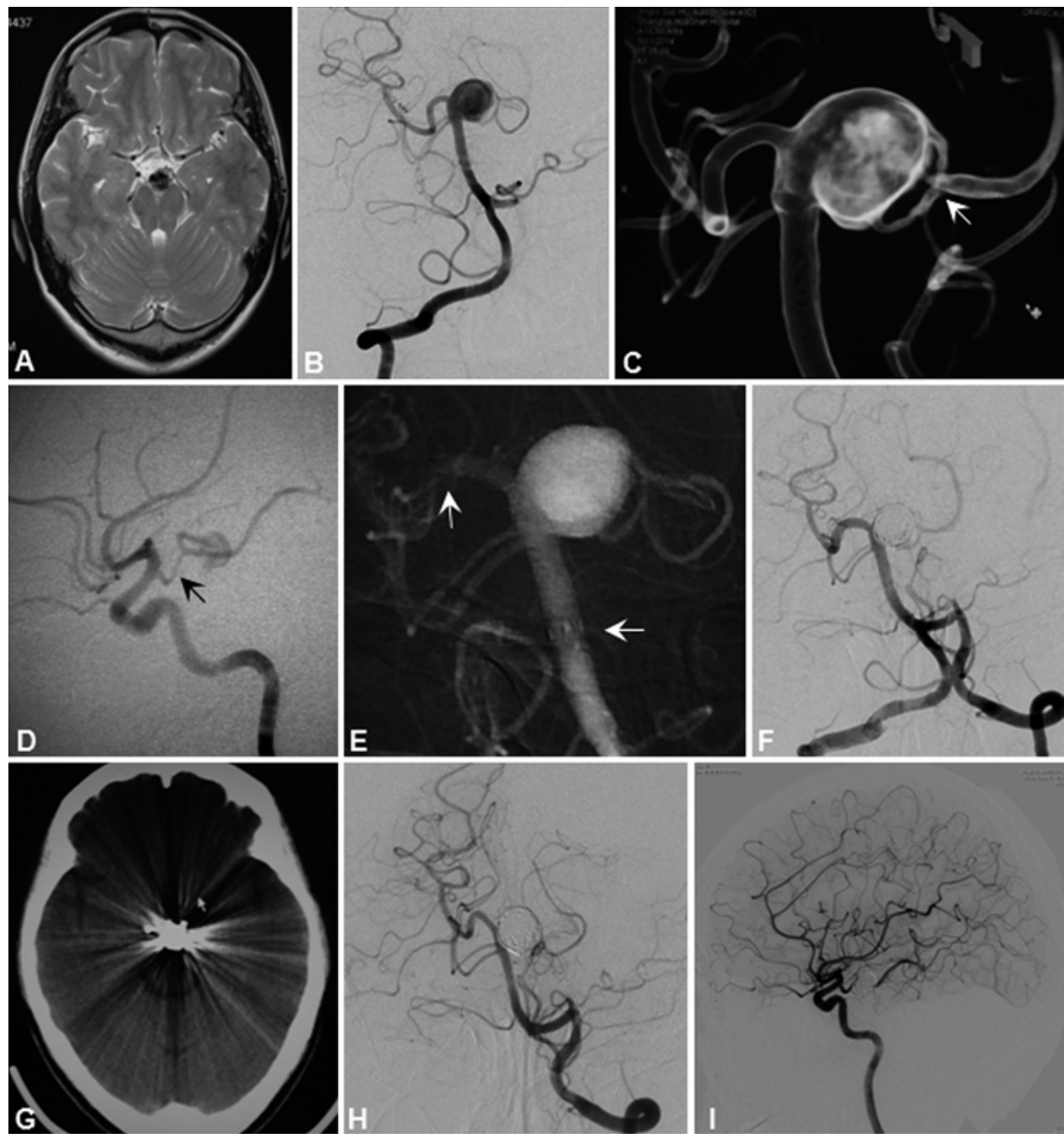

FIG. 2. Case 49. A: Axial T2-weighted MR image revealing a large flow void in the interpeduncular cistern. B: Vertebral angiogram showing a fusiform aneurysm at the $P_{1}$ segment of the PCA. C: $3 D$ angiogram demonstrating the tortuosity and small diameter of left distal PCA (arrow). D: Left internal carotid angiogram revealing the patency of left posterior communicating artery (arrow) and retrograde filling of the aneurysm via the $P_{1}$ segment. E: A 4.5 $\times 22-$ mm Enterprise stent was deployed in the right $P_{2}$ segment (arrow) and extended down to the mid-basilar artery (arrow). F: The aneurysm and parent artery were almost completely occluded with coils. G: Postoperative CT scan showing no infarction in PCA territory or midbrain. H: Follow-up angiogram obtained 16 months later showing complete occlusion of the aneurysm and parent artery. I: Left internal carotid artery angiogram showing filling of the left PCA via the patent posterior communicating artery without retrograde filling of the aneurysm.

\section{Case 11}

A 56-year-old woman complained of headache lasting more than a year. Angiography revealed a fusiform aneurysm at the $\mathrm{P}_{1} / \mathrm{P}_{2}$ junction of the right PCA (Fig. 3). A reconstruction strategy of stent-assisted coiling was planned. An Echenon-14 microcatheter was placed into the aneurysm. However, the aneurysm ruptured during navigation of the microguidewire into the distal PCA. Heparin was immediately reversed, and coiling was continued until the bleeding stopped. The aneurysm was partially occluded together with the parent artery, resulting in minimal filling of the distal PCA. The patient had no postoperative neurological deficit. Four-month follow-up angiogram showed complete obliteration of the aneurysm and parent artery. Right internal carotid angiography demonstrated collateral filling of the PCA segments distal to the occlusion.

\section{Case 38}

A 38-year-old man presented with headache and left lower-extremity weakness lasting 1 month. A CT scan revealed a high-density lesion in the right ambient cistern (Fig. 4). MR imaging and angiography demonstrated a fusiform dissecting aneurysm involving the $\mathrm{P}_{2}$ segment of the right fetal-type PCA. The $\mathrm{P}_{1}$ segment was absent on the vertebral angiogram. Considering that immediate complete occlusion of a fetal-type aneurysm and its parent artery may cause serious ischemic complications, the aneurysm was partially occluded together with the parent artery. The patient recovered well without any complication. Follow-up 

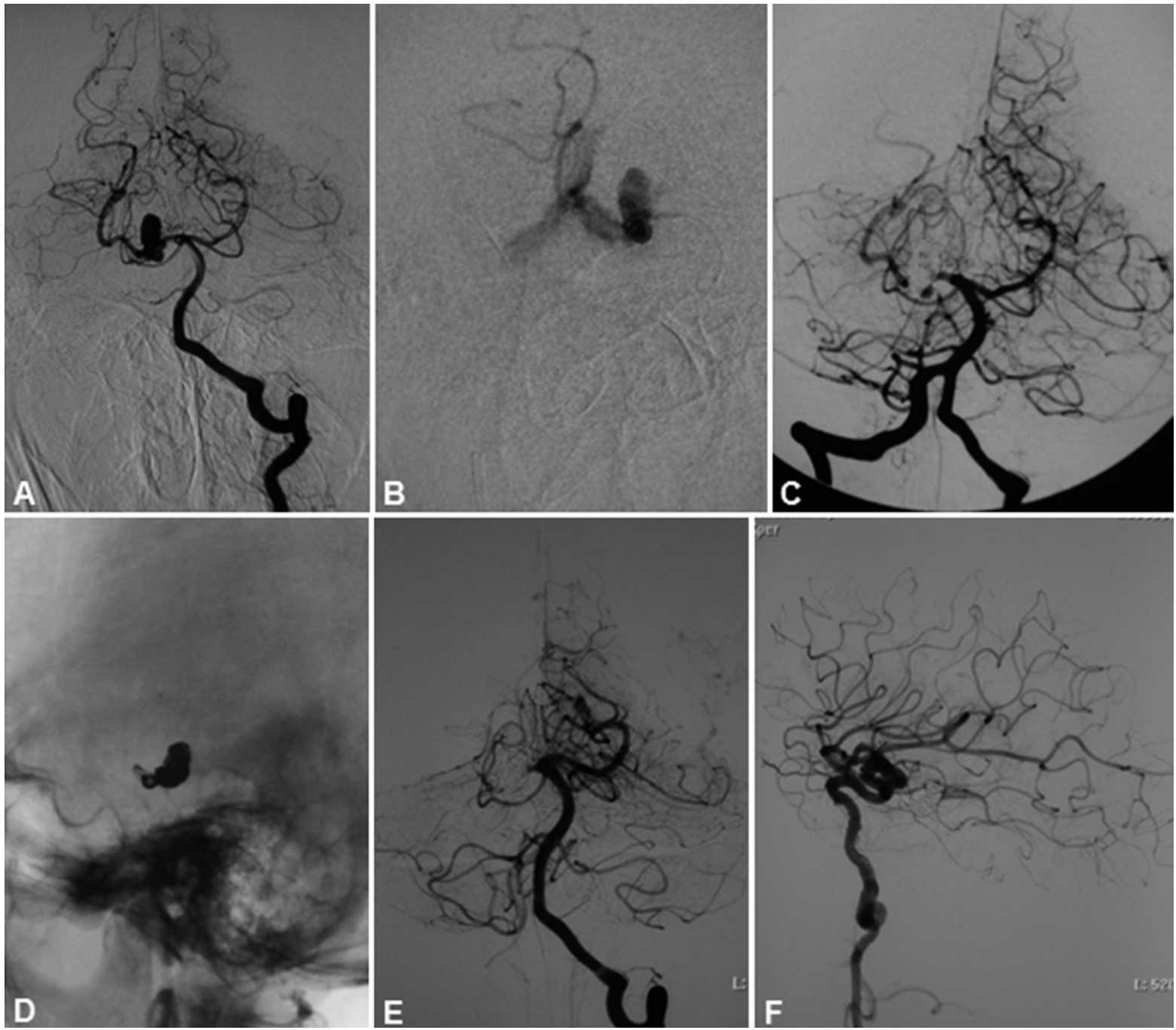

FIG. 3. Case 11. A: Vertebral angiogram revealing a fusiform aneurysm at the $P_{1} / P_{2}$ junction of the right $P C A$. B: Angiogram showing the extravasation of contrast media due to the guidewire perforating the wall. $\mathbf{C}$ : The aneurysm was partially occluded together with the parent artery. D: Radiograph in lateral view showing coils. E: Four-month follow-up angiogram showing the complete obliteration of the aneurysm and parent artery. F: Right internal carotid angiogram demonstrating collateral filling of the PCA segments distal to the occlusion.

angiography performed 25 months later showed complete occlusion of the aneurysm and parent artery with good leptomeningeal collateral supply to distal PCA territory.

\section{Case 40}

A 19-year-old man complained of a throbbing headache and left facial numbness lasting 3 months. A CT scan showed a round high-density lesion in the left ambient cistern. MR imaging and angiography demonstrated a fusiform aneurysm at the $\mathrm{P}_{2}$ segment of the left PCA. The aneurysm was completely occluded with coils, including the parent artery (Fig. 5). The patient made an uneventful recovery without any complications. Eight-month follow-up angiography showed no recanalization of the aneurysm. The distal territory of the PCA was vascularized by the leptomeningeal supply.

\section{Discussion \\ Clinical Features}

Compared with intracranial aneurysms that occur at other anatomical locations, PCA aneurysms have some unique morphological characteristics and a number of specific clinical findings. ${ }^{29}$ According to previous studies, PCA aneurysms are more likely to affect young patients. ${ }^{15}$ However, the average patient age of 47.5 years in our series was not significantly younger than the average age (range 50-60 years) of patients with aneurysms at other anatomical sites. Hamada et al. ${ }^{18}$ reported a series of 21 patients with an average age of 49.8 years. In another series of 22 patients, van Rooij et al ${ }^{35}$ reported that the average patient age was 49.4 years. Our findings were also consistent with these studies. Also, PCA aneurysms tended to be large or giant. ${ }^{718}$ In our series, 29 (49.2\%) of the 59 aneurysms were 

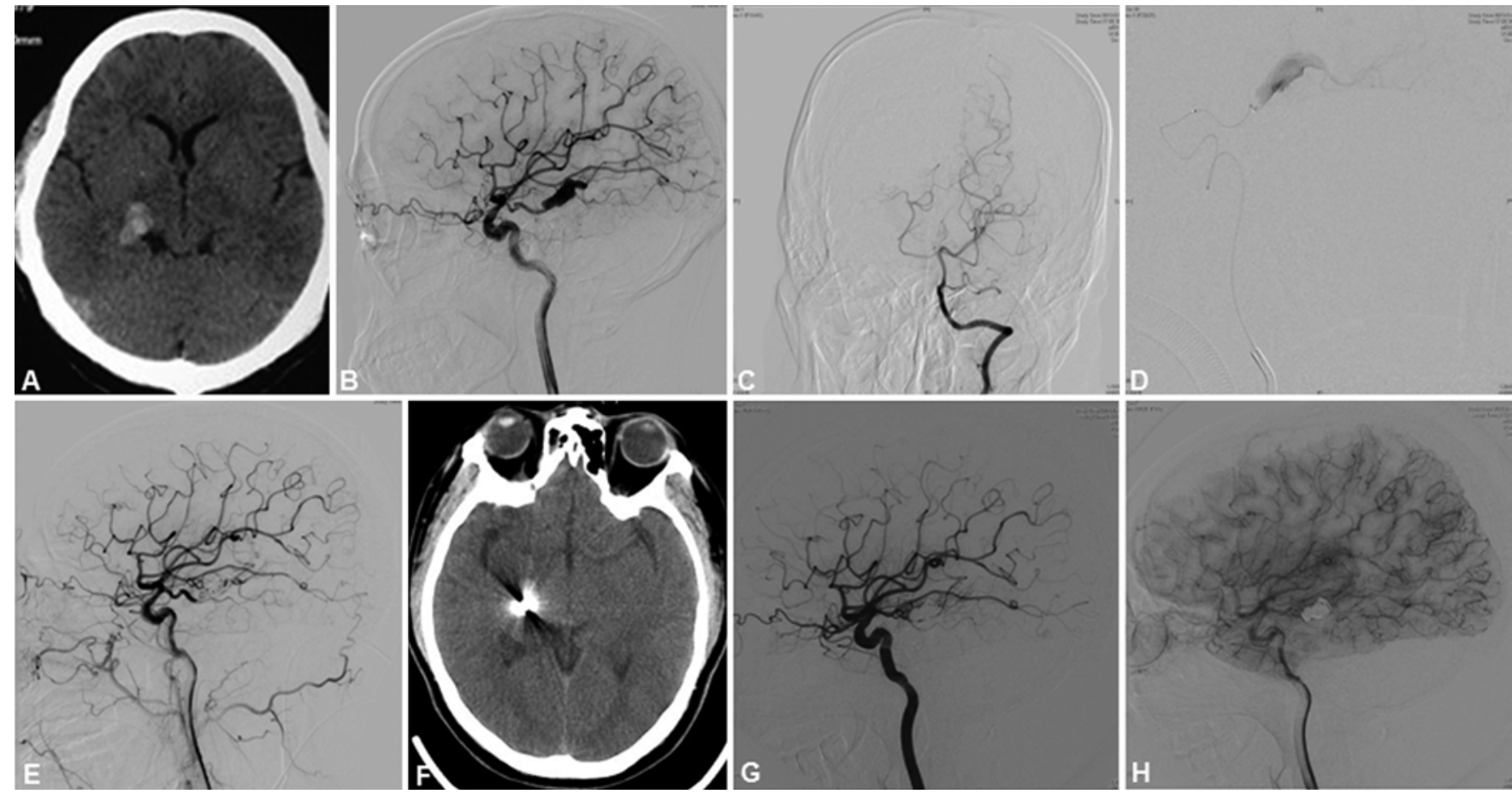

FIG. 4. Case 38. A: CT scan revealing a high-density lesion in the right ambient cistern. B: Right internal carotid angiogram demonstrating a fusiform aneurysm at the $P_{2}$ segment of a fetal-type PCA. C: Vertebral angiogram showing that the right $P_{1}$ segment is absent. D: Superselective catheterization angiogram confirming fusiform aneurysmal dilation before coiling. E: The patient was treated by partial coiling of the aneurysm and parent artery. F: Postoperative CT scan revealing no infarction in the PCA territory. G: Twenty-five-month follow-up angiogram showing the complete occlusion of the aneurysm and parent artery. H: Right internal carotid angiogram showing good collateral supply through the leptomeningeal collateral circulation.

large or giant, which is similar to the results reported by others. PCA aneurysms are often fusiform in shape. Of the 59 aneurysms in our series, $25(42.3 \%)$ were saccular and $34(57.7 \%)$ were fusiform/dissecting.

The most frequent location for PCA aneurysms reported elsewhere is the proximal segment, including $\mathrm{P}_{1}$ and the $\mathrm{P}_{1} / \mathrm{P}_{2}$ junction. ${ }^{13,16}$ Goehre et al. ${ }^{16}$ reported that the proximal PCA harbored $69 \%$ of all PCA aneurysms. Of our 59 aneurysms, only $19(33.2 \%)$ had PCA aneurysms at these locations; 27 (45.8\%) of 59 aneurysms were located at the $\mathrm{P}_{2}$ segment. These findings coincide with the results reported by Hamada et al. ${ }^{18}$ and Ferrante at al. ${ }^{15}$ They found that the $\mathrm{P}_{2}$ segment was the most common location for PCA aneurysms.

Previous studies showed that the most common clinical presentation of PCA aneurysms is SAH. ${ }^{7}$ In our series, $33.9 \%$ of the 59 aneurysms were ruptured. We also showed that PCA aneurysms have a relatively high incidence of coexisting vascular anomalies, such as moyamoya disease, AVM, and arterial occlusion. In 14 (25\%) patients, the aneurysm was associated with other lesions.

\section{Endovascular Treatment}

In our opinion, selective endovascular occlusion of the aneurysm with preservation of the parent artery is the first choice for the treatment of saccular PCA aneurysms. For saccular aneurysms with narrow necks and small sizes, selective embolization of the aneurysm can be safely and effectively performed with coils. Wide-neck saccular aneurysms can be selectively obliterated using stentassisted coiling or the balloon-remodeling technique.? In our series, all patients with saccular aneurysms, except 2 patients, were treated with selective occlusion of the aneurysm. These 2 patients had multiple flow-related PCA aneurysms that were located on 1 of the arteries feeding the AVM and treated by occlusion of the aneurysm together with the parent artery.

In cases of fusiform or giant serpentine aneurysms, selective occlusion with preservation of the parent artery appears to be difficult. PAO offers an alternative to endovascular endosaccular coil embolization, thereby preventing recurrence. Previous studies demonstrated that PAO is safe and effective for the treatment of the $\mathrm{P}_{2}$ segment or distal aneurysms due to the rich collateral supply. $2,6,7,17,25,35$ Hallacq et al. ${ }^{17}$ reported performing endovascular sacrifice of the PCA in 9 patients with $\mathrm{P}_{2}$ segment aneurysms. None of the patients experienced visual deficits or any other complications. Arat et al. ${ }^{2}$ performed endovascular PAO in 8 patients with large/giant or fusiform distal PCA aneurysms. One patient developed occipital infarcts that resulted in permanent homonymous hemianopia. Lv et al. ${ }^{25}$ reported a series of 8 patients with $\mathrm{P}_{2}$ dissecting aneurysms treated by parent vessel occlusion. No patient developed neurological deficits. Xu et al ${ }^{40}$ reviewed 98 cases with $\mathrm{P}_{2}$-segment and distal aneurysms that were reported in the literature between 2001 and 2012. Of the 76 patients 

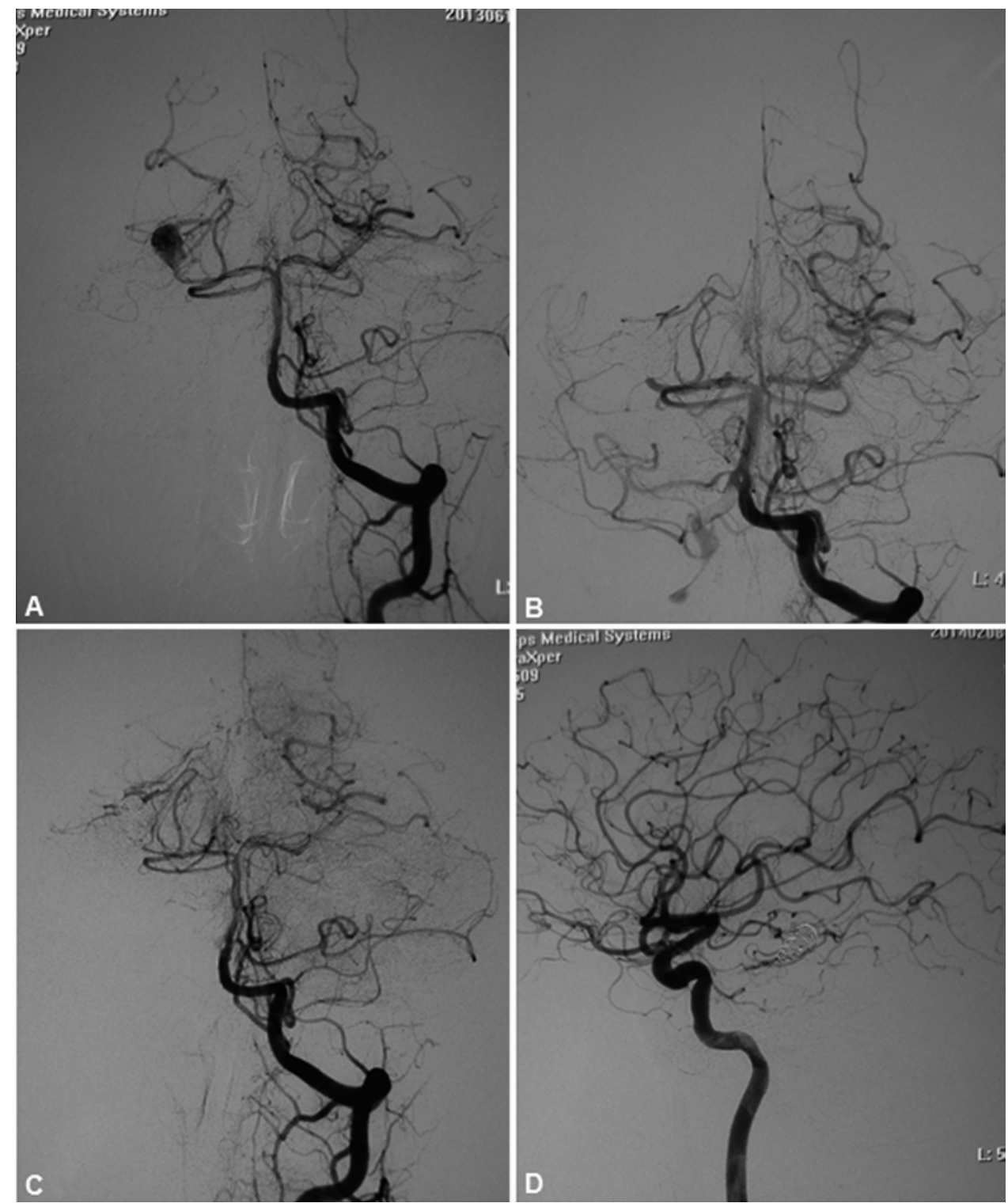

FIG. 5. Case 40. A: Vertebral angiogram showing a fusiform aneurysm at the $P_{2}$ segment of the left PCA. B: Occlusion of the aneurysm with coils, including the afferent $\mathrm{P}_{2}$ segment. C: Eight-month follow-up angiogram showing persistent obliteration of the aneurysm and parent artery. D: Right internal carotid angiogram demonstrating good leptomeningeal collateral supply to the distal PCA territory.

treated by PAO, 13 patients experienced new visual field deficits. Xu et al. concluded that endovascular PCA sacrifice is a safe method for managing $\mathrm{P}_{2}$-segment and distal aneurysms. In the present study, 29 (85.3\%) of 34 fusiform/dissecting aneurysms were located on the $\mathrm{P}_{2}$ or distal segments. All except 1 patient were treated by PAO with or without coiling of the aneurysm. Although BOT can be used to assess collateral blood flow with neurological monitoring, its value in the evaluation of tolerance to PAO remains controversial. Both false-positive and -negative test results have been reported previously. Moreover, BOT in the tortuous PCA is technically challenging, increasing the risk of procedure-related complications. Thus, BOT before PAO was not routinely done in our study.
Endovascular treatment of fusiform aneurysms of the proximal PCA remains challenging given the perforating arteries that supply the thalamus and brainstem. The posterior thalamoperforators and long circumflex arteries arise from the $\mathrm{P}_{1}$ segment, whereas the peduncular, thalamogeniculate perforators and short circumflex arteries arise from the $\mathrm{P}_{2}$ segment. ${ }^{2}$ The immediate, complete occlusion of these perforators often leads to serious ischemic complications. In addition, endovascular occlusion of the aneurysm and its parent artery is of high risk for patients with a fetal-type PCA aneurysm because of the insufficient collateral flow. ${ }^{26,40}$ Such aneurysms are not amenable to immediate occlusion. Gradual thrombosis in the aneurysm may provide a time window for collateral progression. In 
TABLE 6. Summary of experiences with flow diverters for PCA aneurysms

\begin{tabular}{|c|c|c|c|c|c|}
\hline Authors \& Year & $\begin{array}{l}\text { No. of } \\
\text { Cases }\end{array}$ & $\begin{array}{l}\text { Treatment } \\
\text { Device }\end{array}$ & $\begin{array}{c}\text { No. of Procedure-Related } \\
\text { Complications }\end{array}$ & $\begin{array}{l}\text { No. of } \\
\text { Deaths }\end{array}$ & $\begin{array}{l}\text { No. of Angiographic } \\
\text { Obliterations }\end{array}$ \\
\hline de Barros et al., 2011 & 1 & Pipeline & 0 & 0 & 1 \\
\hline McAuliffe \& Wenderoth, 2012 & 2 & Pipeline & 0 & 0 & 1 \\
\hline Phillips et al., 2012 & 5 & Pipeline & 1 & 0 & 4 \\
\hline Wagner et al., 2012 & 1 & Silk & 1 & 0 & 0 \\
\hline Ding et al., 2014 & 1 & Pipeline & 1 & 0 & 0 \\
\hline Colby et al., 2015 & 1 & Pipeline Flex & 1 & 0 & 0 \\
\hline Wakhloo et al., 2015 & 3 & Surpass & 0 & 0 & 3 \\
\hline Toth et al., 2015 & 1 & Pipeline & 1 & 0 & 0 \\
\hline
\end{tabular}

our series, 5 patients were treated by partial coiling of the aneurysm and PAO. The smallest length of the parent artery was nearly completely occluded. None of these patients had any postoperative complications. Although there was still minimal flow of the distal PCA, follow-up angiography showed complete occlusion of the aneurysm and parent artery. Complete thrombosis of the aneurysm may be due to the decreased flow dynamics of the residue aneurysm. However, recanalization of the aneurysm is not uncommon after partial coiling. Thus, short-term followup images should be carefully monitored.

Recently, endovascular reconstruction of fusiform or dissecting aneurysms has emerged. ${ }^{23,31,38}$ Stent-assisted coil embolization is an attractive alternative treatment for fusiform/dissecting aneurysms involving the proximal segment of the PCA, in which PAO is not feasible. The stent acts as a scaffold, providing a structured support for coil embolization and allowing parent vessel reconstruction. In our present study, 1 patient with a $\mathrm{P}_{1}$ fusiform aneurysm was treated with stent-assisted coiling. However, the durability and safety of this reconstruction technique cannot be ascertained. Recanalization is more common, and close angiographic follow-up is required to assess the need for retreatment. ${ }^{31,38}$ Moreover, rebleeding after stentassisted coiling and second stent placement has also been reported. ${ }^{23}$ Further advances in stents may offer a new treatment option.

Flow-diverting stents are new devices designed to treat complex intracranial aneurysms. Treating an intracranial aneurysm with flow diverters is effective, with high rates of complete aneurysm occlusion. ${ }^{5}$ However, procedurerelated morbidity and mortality are higher in posterior circulation aneurysms. ${ }^{5,20}$ Aneurysm morphology and presentation may affect the outcome of endovascular treatment with flow diverters. ${ }^{1}$ Symptomatic and fusiform large aneurysms are associated with a higher risk of ischemic stroke and perforator infarctions. ${ }^{34}$ We reviewed the literature regarding the use of flow diverters for PCA aneurysms (Table 6). . $10,12,27,28,34,36,37$ Articles with no clear description of angiographic findings were excluded. Among 15 patients treated with flow-diverting devices, 5 patients experienced ischemic stroke. Although 2 cases were due to in-stent thrombosis secondary to antiplatelet medication noncompliance, the use of flow diverters in perforator-rich arteries is associated with an increased risk of thrombo- embolic complications. In addition, all 5 aneurysms were large, and 3 of them were fusiform. Thus, we advise caution with large fusiform aneurysms of the PCA, which seem to have higher risks. Further larger studies are needed to assess the role of flow-diverting devices in the treatment of PCA aneurysms.

\section{Surgical Treatment}

Surgical treatment of PCA aneurysms includes clipping, wrapping, clip wrapping, trapping, and revascularization. The treatment strategy depends on the type of the aneurysm (e.g., saccular, dissecting, or fusiform). ${ }^{17}$ For smaller saccular PCA aneurysms, it may be possible to perform direct clipping without great technique difficulty or significant procedure-related morbidity. ${ }^{22}$ Since PCA aneurysms are more likely to be large and fusiform, direct clipping is usually impossible. Wrapping of the aneurysm is an alternative treatment strategy. However, it remains controversial due to aneurysm regrowth and rehemorrhage. The clipwrapping technique has been reported to be a safe treatment for unclippable fusiform aneurysms. ${ }^{11}$ This technique will be more challenging in fusiform aneurysms involving long segments or perforating arteries. It should be noted that this modality neither completely occludes the aneurysm nor prevents rebleeding. Considering that definitively excluding the aneurysm from the arterial circulation is the goal, the ideal treatment modality is proximal artery ligation or trapping of the aneurysms with distal PCA bypass.

Drake et al. ${ }^{14}$ performed PCA occlusion or aneurysm trapping in 52 patients. After excluding $\mathrm{P}_{1}$-segment aneurysms, approximately $17 \%$ of the patients with distal PCA sacrifice developed a new visual field deficit. Theoretically, bypass would decrease the number of patients experiencing visual deficits. However, due to limited experience with this technique, the overall risk of complications, including hemorrhage and infarction, is increased. Chang et al. ${ }^{6}$ reported the largest series of using distal PCA bypass for the treatment of PCA aneurysms. They demonstrated that bypass techniques for the treatment of distal PCA aneurysms are associated with a higher rate of complications. They also showed that significant risk increases when bypass is combined with a subsequent endovascular procedure. This might be due to administering anticoagulation therapy during endovascular procedures to prevent embolic events. Under anticoagulation therapy, the risk of 
hemorrhagic complications associated with bypass may increase. ${ }^{21}$ Thus, further studies are needed to confirm the benefit of surgical revascularization of the PCA.

\section{Outcome}

The immediate angiographic results in our patients included 45 complete occlusions (82\%), 2 nearly complete occlusions (4\%), and 8 incomplete occlusions (14\%). In our study, 46 patients had follow-up imaging, with a follow-up rate of $89 \%$. The final results included 41 complete occlusions (89\%), 2 nearly complete occlusions (4\%), and 3 incomplete occlusions (7\%). Follow-up angiography showed stable or improved results in most of our patients. However, we observed recanalization in 2 patients who were treated by occlusion of the aneurysm and parent artery. We postulated there might be some possible causes for recanalization. First, insufficient initial packing might contribute to coil compaction and recanalization. ${ }^{3}$ When possible, we occluded the smallest length of the parent artery with coils. Additionally, it is sometimes difficult to occlude the entire dissected lesion. Short-segment occlusion might gradually lead to coil compaction. ${ }^{19}$ Second, we might place the microcatheter into the false lumen and occlude the lumen during the initial treatment. The compressed true lumen may have reexpanded and recanalized with gradual healing several months later. ${ }^{2}$

In our series, most patients (94.5\%) were independent with a GOS score of 4 to 5 at discharge. Procedure-related complications included the following: 1$)$ rebleeding $(\mathrm{n}=$ $1) ; 2$ ) infarction $(n=4)$; and 3$)$ perforation $(n=1)$. The overall complication rate in this series was $10.9 \%$, with a permanent morbidity rate of $3.6 \%$. There was $1(1.8 \%)$ instance of procedure-related mortality due to rebleeding, and $2(3.6 \%)$ non-procedure-related mortalities due to severe SAH. Ciceri et al. ${ }^{7}$ reported a permanent morbidity rate of $10 \%$ and a $0 \%$ mortality rate in a series of 20 cases. Van Rooij et al. ${ }^{35}$ reported a series of 22 patients with a procedure-related mortality rate of $4.5 \%$ and a nonprocedure-related mortality rate of $9.1 \%$. Roh et al. ${ }^{29}$ reviewed the literature and analyzed 72 patients who were treated with the endovascular approach. The permanent morbidity rate was $11 \%$, and the mortality rate was only $4 \%$. Xu et al. ${ }^{40}$ reviewed 76 distal PCA aneurysms treated by PAO. The complication rate for visual deficits was $17.57 \%$ (13 of 74 patients), with a mortality rate of $3.95 \%$. Our results are comparable to these previously published series. In addition, our results suggest that stent-assisted coiling is not associated with a higher complication rate and highlight the safety and utility of these techniques.

\section{Limitations}

There are several limitations that may have affected our results. First, our study is limited by its retrospective design. Second, no flow diverters were used in our series. These data were not available in our retrospective study. Third, this study involved a limited number of cases that received partial coiling of the aneurysm and parent artery, which precludes any firm conclusion regarding the safety and efficacy of this modality for the treatment of PCA aneurysms. Further studies and larger case series are necessary to assess the efficacy and durability of this treatment.

\section{Conclusions}

PCA aneurysms are rare, with an incidence of $1.7 \%$ among all intracranial aneurysms in our study. PCA aneurysms are more likely to be large and fusiform in shape, and they occur more frequently in the $\mathrm{P}_{2}$ segment. Clinical presentation is variable and includes SAH, headache, dizziness, mass effect, visual changes, and ptosis. Saccular aneurysms with narrow necks can be safely and effectively treated with selective occlusion and preservation of the parent artery. Wide-neck saccular aneurysms can be selectively obliterated using the stent-assisted coiling technique. For fusiform/dissecting aneurysms of the distal PCA, occlusion of the aneurysm together with the parent artery is safe and effective. For fusiform/dissecting aneurysms of the proximal PCA or with a fetal-type PCA, partial coiling of the aneurysm and parent artery is an attractive alternative treatment with good clinical and anatomical outcomes. Further studies with larger case series are necessary for validation of the durability and efficacy of this treatment.

\section{References}

1. Albuquerque FC, Park MS, Abla AA, Crowley RW, Ducruet AF, McDougall CG: A reappraisal of the Pipeline embolization device for the treatment of posterior circulation aneurysms. J Neurointerv Surg 7:641-645, 2015

2. Arat A, Islak C, Saatci I, Kocer N, Cekirge S: Endovascular parent artery occlusion in large-giant or fusiform distal posterior cerebral artery aneurysms. Neuroradiology 44:700705,2002

3. Baik SK, Kim YS, Lee HJ, Park J, Kang DS: Antegrade recanalization of parent artery in internal trapping of vertebral artery dissecting aneurysm: a case report. Surg Neurol 68:108-111, 2007

4. Biondi A, Jean B, Vivas E, Le Jean L, Boch AL, Chiras J, et al: Giant and large peripheral cerebral aneurysms: etiopathologic considerations, endovascular treatment, and long-term follow-up. AJNR Am J Neuroradiol 27:1685-1692, 2006

5. Brinjikji W, Murad MH, Lanzino G, Cloft HJ, Kallmes DF: Endovascular treatment of intracranial aneurysms with flow diverters: a meta-analysis. Stroke 44:442-447, 2013

6. Chang SW, Abla AA, Kakarla UK, Sauvageau E, Dashti SR, Nakaji P, et al: Treatment of distal posterior cerebral artery aneurysms: a critical appraisal of the occipital artery-to-posterior cerebral artery bypass. Neurosurgery 67:16-26, 2010

7. Ciceri EF, Klucznik RP, Grossman RG, Rose JE, Mawad ME: Aneurysms of the posterior cerebral artery: classification and endovascular treatment. AJNR Am J Neuroradiol 22:27-34, 2001

8. Colby GP, Lin LM, Caplan JM, Jiang B, Huang J, Tamargo RJ, et al: Immediate procedural outcomes in 44 consecutive Pipeline Flex cases: the first North American single-center series. J Neurointerv Surg [epub ahead of print], 2015

9. Cotroneo E, Gigli R, Guglielmi G: Endovascular occlusion of the posterior cerebral artery in the treatment of $\mathrm{P} 2$ ruptured aneurysms. Interv Neuroradiol 13:127-132, 2007

10. de Barros Faria M, Castro RN, Lundquist J, Scrivano E, Ceratto R, Ferrario A, et al: The role of the pipeline embolization device for the treatment of dissecting intracranial aneurysms. AJNR Am J Neuroradiol 32:2192-2195, 2011

11. Deshmukh VR, Kakarla UK, Figueiredo EG, Zabramski JM, Spetzler RF: Long-term clinical and angiographic follow-up of unclippable wrapped intracranial aneurysms. Neurosurgery 58:434-442, 2006

12. Ding D, Starke RM, Liu KC: Microsurgical strategies follow- 
ing failed endovascular treatment with the pipeline embolization device: case of a giant posterior cerebral artery aneurysm. J Cerebrovasc Endovasc Neurosurg 16:26-31, 2014

13. Drake CG, Amacher AL: Aneurysms of the posterior cerebral artery. J Neurosurg 30:468-474, 1969

14. Drake CG, Peerless SJ, Hernesniemi JA: Surgery of Vertebrobasilar Aneurysms: London, Ontario, Experience on 1767 Patients. New York: Springer, pp 221-248, 1996

15. Ferrante L, Acqui M, Trillò G, Lunardi P, Fortuna A: Aneurysms of the posterior cerebral artery: do they present specific characteristics? Acta Neurochir (Wien) 138:840-852, 1996

16. Goehre F, Jahromi BR, Hernesniemi J, Elsharkawy A, Kivisaari R, von und zu Fraunberg M, et al: Characteristics of posterior cerebral artery aneurysms: an angiographic analysis of 93 aneurysms in 81 patients. Neurosurgery 75:134-144, 2014

17. Hallacq P, Piotin M, Moret J: Endovascular occlusion of the posterior cerebral artery for the treatment of $\mathrm{p} 2$ segment aneurysms: retrospective review of a 10 -year series. AJNR Am J Neuroradiol 23:1128-1136, 2002

18. Hamada J, Morioka M, Yano S, Todaka T, Kai Y, Kuratsu $\mathrm{J}$ : Clinical features of aneurysms of the posterior cerebral artery: a 15-year experience with 21 cases. Neurosurgery 56:662-670, 2005

19. Horie N, Kawahara I, Kitagawa N, Morikawa M, Tsutsumi K, Kaminogo M, et al: Recanalization after endovascular occlusion of a dissecting aneurysm of the posterior cerebral artery - a case report and review of the literature. Clin Neurol Neurosurg 110:411-415, 2008

20. Kallmes DF, Hanel R, Lopes D, Boccardi E, Bonafé A, Cekirge $S$, et al: International retrospective study of the pipeline embolization device: a multicenter aneurysm treatment study. AJNR Am J Neuroradiol 36:108-115, 2015

21. Kashiwazaki D, Ushikoshi S, Asano T, Osanai T, Kuroda S, Houkin K: Endovascular treatment for aneurysms of the posterior cerebral artery: 12 years' experience with 21 cases. Acta Neurochir (Wien) 153:2151-2158, 2011

22. Kocaeli H, Chaalala C, Abruzzo TA, Zuccarello M: Results of surgical management for posterior cerebral artery aneurysms: 7-year experience in the endovascular era. Acta Neurochir (Wien) 151:1583-1591, 2009

23. Lee JY, Kwon BJ, Kang HS, Wang KC: Subarachnoid hemorrhage from a dissecting aneurysm of the posterior cerebral artery in a child: rebleeding after stent-assisted coiling followed by stent-within-stent technique. J Korean Neurosurg Soc 49:134-138, 2011

24. Leng B, Zheng Y, Ren J, Xu Q, Tian Y, Xu F: Endovascular treatment of intracranial aneurysms with detachable coils: correlation between aneurysm volume, packing, and angiographic recurrence. J Neurointerv Surg 6:595-599, 2014

25. Lv X, Li Y, Jiang C, Yang X, Wu Z: Parent vessel occlusion for $\mathrm{P} 2$ dissecting aneurysms of the posterior cerebral artery. Surg Neurol 71:319-325, 2009

26. Lv X, Li Y, Yang X, Jiang C, Wu Z: Potential proneness of fetal-type posterior cerebral artery to vascular insufficiency in parent vessel occlusion of distal posterior cerebral artery aneurysms. J Neurosurg 117:284-287, 2012

27. McAuliffe W, Wenderoth JD: Immediate and midterm results following treatment of recently ruptured intracranial aneurysms with the Pipeline embolization device. AJNR Am J Neuroradiol 33:487-493, 2012

28. Phillips TJ, Wenderoth JD, Phatouros CC, Rice H, Singh TP, Devilliers L, et al: Safety of the pipeline embolization device in treatment of posterior circulation aneurysms. AJNR Am J Neuroradiol 33:1225-1231, 2012

29. Roh HG, Kim SS, Han H, Kang HS, Moon WJ, Byun HS: Endovascular treatment of posterior cerebral artery aneurysms using detachable coils. Neuroradiology 50:237-242, 2008
30. Selviaridis P, Spiliotopoulos A, Antoniadis Ch, Kontopoulos V, Foroglou G: Fusiform aneurysm of the posterior cerebral artery: report of two cases. Acta Neurochir (Wien) 144:295-299, 2002

31. Taqi MA, Lazzaro MA, Pandya DJ, Badruddin A, Zaidat OO: Dissecting aneurysms of posterior cerebral artery: clinical presentation, angiographic findings, treatment, and outcome. Front Neurol 2:38, 2011

32. Taylor CL, Kopitnik TA Jr, Samson DS, Purdy PD: Treatment and outcome in 30 patients with posterior cerebral artery aneurysms. J Neurosurg 99:15-22, 2003

33. Terasaka S, Sawamura Y, Kamiyama H, Fukushima T: Surgical approaches for the treatment of aneurysms on the P2 segment of the posterior cerebral artery. Neurosurgery 47:359-366, 2000

34. Toth G, Bain M, Hussain MS, Moskowitz S, Masaryk T, Rasmussen P, et al: Posterior circulation flow diversion: a singlecenter experience and literature review. J Neurointerv Surg 7:574-583, 2015

35. van Rooij WJ, Sluzewski M, Beute GN: Endovascular treatment of posterior cerebral artery aneurysms. AJNR Am J Neuroradiol 27:300-305, 2006

36. Wagner A, Cortsen M, Hauerberg J, Romner B, Wagner MP: Treatment of intracranial aneurysms. Reconstruction of the parent artery with flow-diverting (Silk) stent. Neuroradiology 54:709-718, 2012

37. Wakhloo AK, Lylyk P, de Vries J, Taschner C, Lundquist J, Biondi A, et al: Surpass flow diverter in the treatment of intracranial aneurysms: a prospective multicenter study. AJNR Am J Neuroradiol 36:98-107, 2015

38. Wakhloo AK, Mandell J, Gounis MJ, Brooks C, Linfante I, Winer J, et al: Stent-assisted reconstructive endovascular repair of cranial fusiform atherosclerotic and dissecting aneurysms: long-term clinical and angiographic follow-up. Stroke 39:3288-3296, 2008

39. Xu F, Qin X, Tian Y, Gu Y, Leng B, Song D: Endovascular treatment of complex intracranial aneurysms using intra/extra-aneurysmal stent. Acta Neurochir (Wien) 153:923-930, 2011

40. Xu J, Xu L, Wu Z, Chen X, Yu J, Zhang J: Fetal-type posterior cerebral artery: the pitfall of parent artery occlusion for ruptured $\mathrm{P}_{2}$ segment and distal aneurysms. J Neurosurg 123:906-914, 2015

41. Zeal AA, Rhoton AL Jr: Microsurgical anatomy of the posterior cerebral artery. J Neurosurg 48:534-559, 1978

\section{Disclosure}

The authors report no conflict of interest concerning the materials or methods used in this study or the findings specified in this paper.

\section{Author Contributions}

Conception and design: Chen, F Xu. Acquisition of data: Chen, Qin, F Xu, Maimaiti, Zheng. Analysis and interpretation of data: Chen, F Xu. Drafting the article: Qin, F Xu. Critically revising the article: Chen, Qin, F Xu. Reviewed submitted version of manuscript: Chen, F Xu. Approved the final version of the manuscript on behalf of all authors: F Xu. Administrative/technical/material support: B Xu, Leng.

\section{Correspondence}

Gong Chen, Department of Neurosurgery, Huashan Hospital, Shanghai Medical School, Fudan University, Shanghai, China 200040. email: onlycg668@sina.com. 